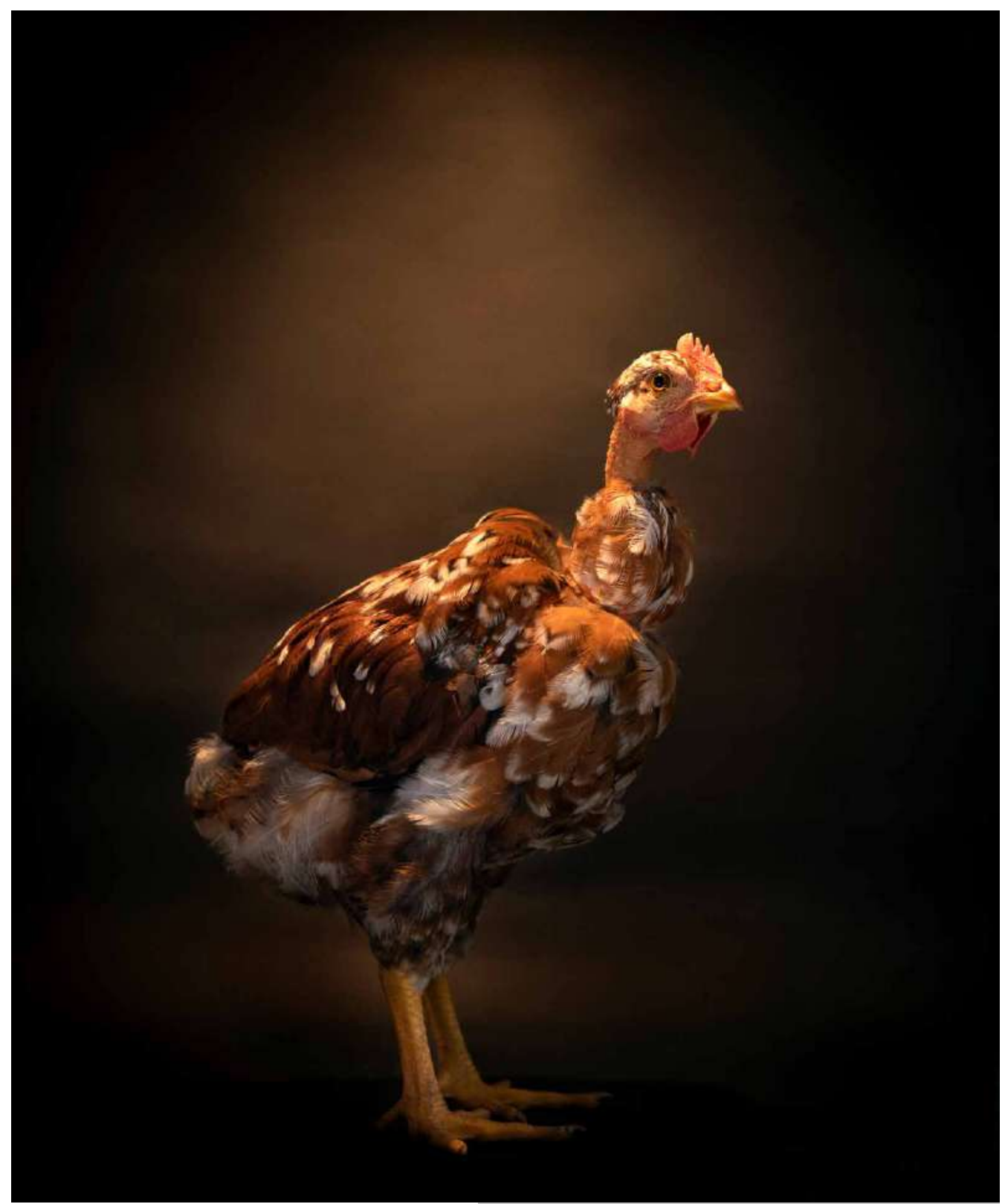

Artista invitada

Carolina Muñoz Valencia

Carioco

De la serie Retratos para entender lo esencial Fotografía digital

2020

Cortesía revista Ojo de Pez 


\section{Villamizar, Darío. (2020). Las guerrillas en Colombia. Una historia desde los orígenes hasta los confines. Bogotá, D. C.: Debate.}

\section{Resumen}

En Las guerrillas en Colombia se condensa gran parte del trabajo académico e intelectual de Darío Villamizar en torno al fenómeno guerrillero en el marco del conflicto armado. Villamizar logra construir una temporalidad definida donde explora la irrupción de las diferentes organizaciones guerrilleras; caracterizando con notable precisión su programa, ideologías y acciones. El mayor aporte de la obra a los estudios sobre el conflicto armado se encuentra en la descripción de las relaciones de los grupos guerrilleros, sus procesos de unidad enmarcados en la Coordinadora Nacional Guerrillera y la Coordinadora Guerrillera Simón Bolívar, así como los intentos de paz y negociación. El libro se convierte en un clásico de referencia para todos los interesados en conocer la emergencia del fenómeno guerrillero en Colombia y su continuidad en el último medio siglo.

\section{Palabras clave}

Conflicto Armado; Organizaciones Guerrillas; Procesos de Paz; Negociaciones de Paz; Historia Política.

\section{El ciclo guerrillero, una discusión histórica}

Darío Villamizar Herrera, politólogo e investigador con especialización en Acción sin Daño y Construcción de Paz, se ha erigido como uno de los grandes cronistas del movimiento guerrillero en Colombia. Su copioso estudio de la insurgencia colombiana y latinoamericana inició con Aquel 19 será: una historia del M-19, de sus hombres y sus gestas (Villamizar, 1995), obra de referencia en el abordaje de la principal guerrilla urbana que operó en el país entre 1973 y 1990, y parte de una trilogía conformada por Sueños de abril: imágenes en la historia del M-19 (Villamizar, 1997) y Jaime Bateman: biografía de un revolucionario (Villamizar, 2002). Sin embargo, la obra que lo ratificó como el cronista de movimiento guerrillero llegó quince años después con la publicación de Las Guerrillas en Colombia: una historia desde los orígenes hasta los confines (2017), un monumental libro de 843 páginas que, con una prosa ágil y sencilla, abarca setenta años de historia del fenómeno guerrillero, utilizando como sus principales fuentes documentos desclasificados de 
agencias de inteligencia como la Agencia Central de Inteligencia (CIA) y la Dirección Nacional de Inteligencia (DNI); documentos internos de las organizaciones guerrilleras y los hallazgos parciales del proyecto Memoria de guerrillas en América Latina y el Caribe. ${ }^{1}$

La segunda edición de Las guerrillas en Colombia..., revisada y actualizada, fue publicada en noviembre de 2020 por la editorial Debate. A tres años de su publicación se han presentado una serie de acontecimientos que no alteran su dimensión narrativa, pero que sí complementan parcialmente algunos de sus apartados y arrojan nuevas luces sobre el impacto de la insurgencia en la historia social y política del país, entre ellos, la ruptura del proceso de negociación con el Ejército de Liberación Nacional (ELN); los avances en el sistema integral de justicia transicional que han permitido aclarar hechos de trascendencia como el magnicidio del dirigente conservador Álvaro Gómez Hurtado o el bombardeo a Casa Verde; asimismo, la precaria implementación del Acuerdo del Teatro Colón que se suma al asesinato de cientos de líderes sociales y 252 excombatientes de las Fuerzas Armadas Revolucionarias de Colombia-Ejército del Pueblo (FARCEP) (El Tiempo, 2021, enero 7) desde que se firmó el acuerdo en 2016. Son hechos que cruzan la reciente edición del libro y que resultan significativos para volver a formular la pregunta que motivó a Villamizar: ¿asistimos al final del ciclo guerrillero?

Las Guerrillas en Colombia... es prologado por el periodista Jon Lee Anderson, que destaca su importancia en los estudios del fenómeno guerrillero en Latinoamérica. Afirma Anderson que la principal virtud de Villamizar reside en que logra describir las trayectorias sociohistóricas de las guerrillas a la vez que caracteriza con detalle enciclopédico el entramado de relaciones que las atraviesan en lo local, nacional e internacional; igualmente, no desestima aquellos procesos de negociación que han permitido la conversión de las guerrillas en movimientos políticos que han gozado de representación en corporaciones y capacidad de gobierno (p. 22). Sin embargo, en el caso colombiano, señala Anderson, el ciclo guerrillero continúa abierto con la guerrilla del ELN y un reducto del Ejército Popular de Liberación (EPL), grupos sobre los cuales no se avizora un pronto proceso de paz (p. 24). Para el autor de Che Guevara: una vida revolucionaria (Anderson, 1997): «Cuando exista un Estado que represente a todos los colombianos,

1 Base de datos que reúne información sobre 450 grupos guerrilleros activos desde 1959 en 23 países. 
ya no habrá más guerrilleros en el país» (p. 25). Villamizar es más cauto en su apreciación y considera que en país hay tres paces: en curso, pendiente y en ciernes (p. 33).

En términos de estructura, la obra se compone de nueve capítulos y siete anexos relativos a los documentos fundacionales de los grupos insurgentes y las coordinadoras guerrillas. En el primer capítulo se exploran las condiciones históricas que alentaron la apertura del ciclo guerrillero en América Latina, siendo determinantes, desde el plano internacional, las tensiones de la Guerra Fría y, en el ámbito regional, el triunfo de la Revolución cubana.

A partir del triunfo de Castro y los «barbudos» en 1959 se incuba la semilla de la revolución en gran parte de los países de la región. Colombia no es la excepción y así se aborda en el segundo capítulo, el cual traza el origen de las guerrillas revolucionarias en el marco de los procesos de amnistía promovidos por la presidencia de Gustavo Rojas Pinilla con las guerrillas liberales y con mayor énfasis en el asfixiante sistema que imperó bajo el pacto del Frente Nacional (1958-1974).

El tercer capítulo se enfoca en desarrollar la trayectoria del Movimiento [372 ] Obrero, Estudiantil y Campesino (MOEC) 7 de enero y sus reivindicaciones al cierre de la dictatura rojista. El MOEC resulta de gran importancia en los inicios del ciclo guerrillero porque sirvió de punto de encuentro e inspiración de dirigentes que posteriormente asumieron mayor liderazgo en organizaciones con mayor estabilidad y presencia territorial.

Estas guerrillas son abordadas en el cuarto capítulo que describe los mitos fundacionales de las tres grandes: las FARC-EP, el ELN y el EPL. Para caracterizar su origen el autor explora sus relaciones con el movimiento social, los partidos políticos —especialmente el Partido Comunista- y las tensiones que caracterizaron su emergencia en un periodo de democracia restringida y al amparo casi permanente del Estado de sitio. Concluye este apartado resaltando las dificultades que, al cierre de la década de 1970, con el Paro Cívico Nacional de 1977 y el Estatuto de Seguridad, tuvieron las guerrillas para consolidar su proyecto, resultado de sus propias contradicciones y errores táctico-militares.

En el quinto capítulo Villamizar se adentra en una temática de la cual es experto: las guerrillas urbanas. El Movimiento 19 de abril (M-19) vuelve 
a tener un lugar especial en sus reflexiones, pero en esta oportunidad amplia el radio de análisis al presentar una visión más exhaustiva de las relaciones de sus fundadores con las FARC-EP, el origen del grupo armado en el seno del ala radical de la Alianza Nacional Popular (Anapo), derivado del fraude electoral de 1970, y la inspiración en otras guerrillas urbanas que operaron sin mayor éxito en el Cono Sur. Este es tal vez el capítulo más logrado del libro, porque presenta con claridad el desarrollo de las guerrillas y sus complejos niveles de articulación en un contexto social altamente convulsionando, periodo que desembocó en los primeros intentos de unidad en el movimiento guerrillero y en las primeras propuestas de paz.

El sexto y séptimo capítulo abordan in extenso estas dos variables. Por un lado, las dinámicas de reestructuración en consonancia con planes o programas estratégicos, resultando, a lo largo de la década de 1980, en guerrillas que alcanzaron un alto poderío militar, mayor presencia territorial y mayor incidencia en el movimiento social. Esto en el marco del surgimiento del paramilitarismo y la guerra contra el narcotráfico. Por el otro, Villamizar profundiza en los espacios de unidad representados en la Coordinadora Nacional Guerrillera y en la Coordinadora Guerrillera Simón Bolívar, procesos coyunturales que bajo el incentivo de la unidad en el movimiento guerrillero colombiano — replicando el modelo de la Unidad Revolucionaria Nacional Guatemalteca (URNG) y el Frente Sandinista de Liberación Nacional (FSLN) - posicionaron, ante la sociedad y los diferentes gobiernos, agendas mínimas y comunes que sucumbieron bajo las lógicas del sectarismo, la división y visiones contrarias de hacer la revolución o la paz.

Finalmente, los capítulos octavo y noveno constituyen un único bloque temático orientado a describir los procesos de paz, negociación y desmovilización surtidos entre 1989 y 2016. En este punto se puede afirmar que hay un cierre parcial del ciclo guerrillero tras el desarme del M-19, el EPL, el Partido Revolucionario de los Trabajadores (PRT), el Movimiento Armado Quintín Lame (MAQL), entre otras guerrillas; sin embargo, la imposibilidad de llegar a un acuerdo con las FARC y el ELN extiende la confrontación que, con el trasfondo de la expansión del paramilitarismo, la debilidad institucional y el cambio de táctica de las FARC en lo más alto de su evolución armada, agudizó el conflicto armado. No se detiene el autor en valorar la política de Seguridad Democrática o sus impactos sociales, 
incluyendo su estrategia de desarme, desmovilización y reintegración (DDR) con claro matiz contrainsurgente, sino que da un salto cualitativo al gobierno de Juan Manuel Santos y las «llaves de la paz».

Así termina la obra, con una revisión del proceso surtido con las FARC$\mathrm{EP}$, sus aciertos y desaciertos, también sus fortalezas y limitaciones, para rematar con la necesidad de rodear una paz en ciernes y buscar espacios de diálogos con los actores remanentes del ciclo guerrillero.

En síntesis, Darío Villamizar logra una crónica monumental del fenómeno guerrillero a lo largo de setenta años, presentando hechos curiosos y personajes de antología, una obra de referencia y muy pertinente para una sociedad que no logra sacudirse de la violencia y del eterno retorno de las guerras recicladas. A falta de un capítulo final donde se aborde el cierre definitivo del ciclo iniciado en 1959, Las Guerrillas en Colombia... nos permite comprender las complejidades que habitan en las múltiples Colombia donde lucharon miles de hombres y mujeres que participaron de una «gran batalla perdida en favor de una genuina renovación de la existencia» (p. 14).

\section{Referencias bibliográficas}

1. Anderson, Jon Lee. (1997). Che Guevara: una vida revolucionaria. Barcelona. Anagrama.

2. El Tiempo. (2021, enero 7). Asesinan a otro excombatiente de Farc: van tres en siete días del 2021. https://www.eltiempo.com/justicia/jep-colombia/asesinato-deexcombatientes-diego-yule-el-tercer-ex-farc-asesinado-en-2020-559418

3. Villamizar, Darío. (1995). Aquel 19 será: una historia del M-19, de sus hombres y sus gestas, un relato entre la guerra, la negociación y la paz. Bogotá, D. C.: Planeta.

4. Villamizar, Darío. (1997). Sueños de abril: imágenes en la historia del M-19. Bogotá, D. C.: Planeta.

5. Villamizar, Darío. (2002). Jaime Bateman: biografía de un revolucionario. Bogotá, D. C.: Icono.

\footnotetext{
*Politólogo. Correo electrónico: chaverra01@gmail.com
} 